\title{
PERFIL DE LOS EMPRENDIMIENTOS SOLIDARIOS EN PUERTO RICO
}

\section{PROFILE OF SOLIDARITY ENTREPRENEURSHIP IN PUERTO RICO}

Efraín Rosado Rodríguez (Universidad de Puerto Rico)*

Grisell Reyes Núñez (Universidad de Puerto Rico) ${ }^{* *}$

\section{Resumen}

Descripción general de los emprendimientos solidarios que participaron del Primer Encuentro Internacional de Economía Social y Solidaria realizado en Puerto Rico en el 2019. Es la primera investigación de esta naturaleza en Puerto Rico con el objetivo de recopilar información para visibilizar y fortalecer la economía solidaria e iniciar la construcción de una base nacional de datos de este sector. La técnica utilizada para recopilar datos fue por medio de un cuestionario. Los participantes en la investigación fueron 68 personas que representaban a distintas entidades. Se recogió información sobre actividad socioeconómica, misión, ingresos anuales y alianzas de los emprendimientos, entre otras. Se presentan recomendaciones para robustecer el sector de la economía social y solidaria en el país.

Palabras claves: emprendimientos de la economía social y solidaria, Puerto Rico, perfil

Código JEL: L31, A13

\begin{abstract}
General description of the solidarity initiatives that participated in the First International Meeting on Social and Solidarity Economy held in Puerto Rico in 2019. It was the first investigation of this nature held in Puerto Rico with the aim of gathering information to make visible and strengthen the solidarity economy and initiate the construction of a national database for this sector. The technique used to collect data was a questionnaire. The participants in the research were 68 people representing different entities. Information was collected on socioeconomic activity, mission, annual income and alliances of the enterprises, among others. Recommendations are presented to strengthen the social and solidarity economy sector in the country.
\end{abstract}

Keywords: social and solidarity economy enterprises, Puerto Rico, profile

JEL Code: L31, A13

\section{INTRODUCCIÓN}

La economía social y solidaria es una realidad social desconocida y poco entendida para la mayoría de las personas en Puerto Rico. Incluso para aquellos que participan en entidades que buscan satisfacer necesidades o atender un problema social, mediante la producción de un bien o servicio, fuera del sector gubernamental y el sector privado tradicional.

\footnotetext{
*Autor de correspondencia. Efraín Rosado Rodríguez, Correo-e: efrain.rosado@upr.edu

**Correo-e: grisell.reyes@upr.edu

Fecha de envío: 27/03/2021. Fecha de aceptación: 18/05/2021.
} 
No obstante, en Puerto Rico tenemos una larga tradición asociativa y solidaria, especialmente en sociedades cooperativas. El surgimiento de las cooperativas estuvo ligado a las luchas políticas revolucionarias y económicas tanto en el país como en la metrópolis. En 1873 se proclamó la Primera República Española y con ella se abolió la esclavitud negra y la esclavitud blanca establecida por el sistema de libreta ${ }^{1}$. También se les concedió a los habitantes de Puerto Rico el derecho de asociarse para todos los fines de la vida humana. En ese mismo año se fundó la primera sociedad de socorros mutuos "Los Amigos del Bien Público". Durante el siglo XX bajo el sistema colonial norteamericano se organizaron cientos de cooperativas y otras organizaciones sociales y solidarias clasificadas mayormente como organizaciones sin fines de lucro.

A pesar de esta larga experiencia en el desarrollo de asociaciones, sociedades y organizaciones sociales sin fines de lucro, lo cierto es que aún no hay una identificación con el concepto de economía social y solidaria. Es decir, aún no se tiene claro las características y principios que las hacen diferentes a las organizaciones económicas de capital. Tampoco existe un sentido de nexo o pertenencia en común que le permita mantener una estructura sistémica necesaria para aumentar su impacto social y establecer un equilibrio con los otros sectores económicos (Rosado, 2018).

A partir de la década de 1970 se dieron a conocer las llamadas organizaciones sin fines de lucro (OSFL). Más adelante, a partir de los años 80, se comenzó a utilizar el concepto "tercer sector". Sin embargo, el concepto de economía social y solidaria (ESS) se comienza a utilizar en Puerto Rico a partir de la primera década de este siglo cuando en el Instituto de Cooperativismo de la Universidad de Puerto Rico (ICOOP) empieza a investigar las nuevas construcciones teóricas sobre la economía solidaria, especialmente desde el enfoque latinoamericano. Por consiguiente, el debate conceptual y teórico es muy reciente y aún no existe una aceptación nacional del concepto de ESS. En el marco legal y en la conciencia colectiva predomina el concepto de las OSFL pero esta aceptación resulta simplista porque no reconoce otras características de los emprendimientos de la economía social ni los principios de la economía solidaria.

En las últimas décadas han surgidos iniciativas con características de los emprendimientos de la ESS como: la primicia de las personas y el trabajo sobre el capital; la gobernanza democrática y participativa; y el desarrollo sostenible y sustentable. Para el año 2019 se llevó a cabo el Primer Encuentro Internacional de Economía Social y Solidaria: Conectando experiencias en Puerto Rico. El propósito de esta actividad fue crear conciencia de la necesidad de incluir una visión solidaria y humana en la economía de nuestro país. Como parte del encuentro el Comité Organizador le solicitó al ICOOP que realizara un perfil de las entidades de la ESS participantes en el evento. Esta petición fue acogida y se presentó como proyecto de investigación cuyos objetivos fueron los siguientes:

1. Identificar la personalidad jurídica de las organizaciones y emprendimientos dentro del marco legal en Puerto Rico.

2. Describir las cualidades generales y características estructurales que tienen las organizaciones, emprendimientos o iniciativas autodenominadas de la economía social y solidaria en Puerto Rico.

3. Clasificar las actividades económicas y el sector industrial al cual pertenecen los emprendimientos solidarios en Puerto Rico.

\footnotetext{
${ }^{1}$ El régimen de la libreta consiste en un sistema compulsorio de trabajo, y se implementa a consecuencia de la falta de mano de obra libre que venía experimentándose en Puerto Rico desde principios del siglo XIX.
} 
La importancia de esta investigación es que recoge datos para visibilizar y fortalecer la economía solidaria en Puerto Rico. Con ella se inicia la construcción de una base nacional de este sector con el fin de formular políticas que fomenten su desarrollo. Además, se pone a prueba la metodología con el fin de ampliar la investigación tomando una muestra más amplia del sector. Asimismo, los resultados contenidos en el perfil ofrecen información relevante a la Red de Economía Social y Solidaria de Puerto Rico, que se conformó en agosto 2020 luego del encuentro, con el fin de que el Comité Coordinador diseñe estrategias para la integración de los emprendimientos solidarios.

En la primera parte de este trabajo se presenta una conceptualización de la economía social y solidaria. Luego se presenta el marco legal de las personalidades jurídicas relacionadas a la economía social en Puerto Rico y las instituciones gubernamentales que las apoyan. Además, se explican los métodos de investigación utilizados para hacer el perfil. Se discuten los resultados de los datos obtenidos de acuerdo al cuestionario y finalmente se presentan unas conclusiones, recomendaciones y futuras líneas de investigación.

\section{BREVE CONCEPTUALIZACIÓN DE LA ECONOMÍA SOCIAL Y SOLIDARIA}

Para hacer un perfil de los emprendimientos solidarios en Puerto Rico entendimos necesario revisar los conceptos de economía social, empresas sociales, organizaciones sin fines de lucro y la economía solidaria. También, fue importante entender el carácter dinámico, la diversidad y el contexto de estos conceptos.

Utilizamos algunas de las definiciones más recientes establecidas por el Sistemas de Cuentas Nacionales 2008 con el fin de establecer unos criterios internacionalmente aceptados. También utilizamos definiciones de algunos de los autores más citados en otras investigaciones y publicaciones.

Comenzamos con el concepto de economía social establecido por el Comité Económico y Social Europeo (2017) y definido de la siguiente manera:

conjunto de empresas privadas organizadas formalmente, con autonomía de decisión y libertad de adhesión, creadas para satisfacer las necesidades de sus socios a través del mercado, produciendo bienes y servicios, asegurando o financiando y en las que la eventual distribución entre los socios de beneficios o excedentes, así como la toma de decisiones, no están ligados directamente con el capital o cotizaciones aportados por cada socio, correspondiendo un voto a cada uno de ellos. La economía social también agrupa a aquellas entidades privadas organizadas formalmente con autonomía de decisión y libertad de adhesión que producen servicios de no mercado a favor de las familias, cuyos excedentes, si los hubiera, no pueden ser apropiados por los agentes económicos que las crean, controlan o financian.

Esta definición establece dos subsectores: el de mercado y el no mercado. En el subsector de mercado aparecen organizaciones que adoptan formas jurídicas diferentes a las entidades clásicas de la economía social como las cooperativas y mutuales (Pérez de Mendiguren et al., 2008). También incluye las empresas sociales. El concepto de "empresa social" aparece en Europa y los Estados Unidos en los años 90 del siglo pasado, aunque su conceptualización se ha desarrollado fundamentalmente en el marco europeo. La Red Europea de Investigación (EMES), las define como: "Una organización creada con la meta explícita de beneficiar a la comunidad, iniciada por un colectivo de ciudadanas y ciudadanos, y en la que el interés material de los inversores de capital está sujeto a límites. Las empresas sociales, además, ponen especial valor 
en su autonomía y en el riesgo económico derivado de su continua actividad socioeconómica" (Pérez de Mendiguren et al., 2008).

En el subsector de no mercado se incluyen las organizaciones no lucrativas o Non-Profit Organization. El Sistema de Cuentas Nacionales (2008), las denomina como instituciones sin fines de lucro y las define como entidades jurídicas o sociales, creadas con el propósito de producir bienes y servicios, cuyos estatutos no les permiten ser fuente de ingresos, beneficios u otra ganancia financiera para las unidades que las establecen, controlan o financian. También se incluyeron las características del estudio del Johns Hopkins Comparative Nonprofit Project, coordinado por los profesores Lester M. Salamon y Anheier en 1997.

Por otra parte, el concepto economía solidaria hace referencia a un conjunto heterogéneo de concepciones y enfoques teóricos, realidades socioeconómicas e institucionales, y prácticas empresariales y asociativas que, desde el último cuarto del siglo XX, vienen desarrollando un creciente sentido de pertenencia a una forma diferente de entender el papel de la economía y los procesos económicos en las sociedades contemporáneas (Pérez de Mendiguren et al., 2008).

En la conceptualización de la economía solidaria se reconocen dos enfoques. El europeo, impulsado por el sociólogo francés Jean-Louis Laville y las Organizaciones No Gubernamentales (ONG's); y el latinoamericano desarrollado por el sociólogo chileno Luis Razeto, la Confederación Latinoamericana de Cooperativas de Trabajadores (COLACOT), el uruguayo Pablo Guerra y algunos pensadores de Brasil como Marcos Arruda y Paul Singer. El concepto de economía solidaria ha tenido en Europa un desarrollo distinto en comparación al Latinoamericano pues tiene una rica tradición en cooperativismo y economía social. Para Jean-Louis Laville el concepto de economía solidaria se ha desarrollado para designar las organizaciones de la "nueva economía social", que surgen en respuesta a la crisis del modelo de desarrollo basado en la sinergia estado-mercado, que implicaba la separación y jerarquización de las economías (UNIRCOOP, 2007, p. 13).

Laville (2004) indica que la economía solidaria desde un enfoque europeo tiene dos dimensiones: la económica y la sociopolítica. Según Guerra (2014), otra visión europea proviene del autor francés Philippe Adair quien circunscribe la economía solidaria a la economía informal. Adair señala que los tres componentes de la economía informal son la economía subterránea, la economía doméstica y la economía solidaria que se caracteriza por producir bienes y servicios no monetarios que circulan en ámbitos de sociabilidad según los principios de reciprocidad y redistribución (Guerra, 2014, p.45). Finalmente, la fuente práctica de la economía solidaria europea la ofrecen las ONG's con el desarrollo de la nueva economía de inserción y los llamados "servicios de proximidad". Estas son "formas híbridas" que incluyen tareas solidarias con otras asalariadas y muchas veces con colaboración parcial del Estado (Guerra, 2014).

Cuando nos referimos a la economía solidaria en América Latina debemos mencionar al sociólogo chileno Luis Razeto como uno de los exponentes principales de este concepto. La expresión comenzó a utilizarse en la década del 80 del pasado siglo cuando publicó el libro Economía de la solidaridad y mercado democrático en 1984. Según Razeto la economía solidaria tiene un contenido asociativo que involucra a pequeños grupos o comunidades con estrechos nexos de familiaridad, amistad o vecindad. Su principal aportación fue introducir la solidaridad en la economía tanto en la teoría como en la práctica. Esto supone que la solidaridad opere y actúe en las diversas instancias del ciclo económico, es decir, desde la producción, la circulación, la distribución y la acumulación, cuya realidad sólo podría lograrse si aparece un nuevo modo de hacer economía o una nueva racionalidad económica (Razeto, 2007, pp. 317-322). Razeto entrelaza, en su desarrollo teórico, la economía popular, informal, ecológicas y de las donaciones con la economía solidaria (Razeto, 2010). 
Entre las aportaciones más significativas de Razeto, debemos reconocer la incorporación de un nuevo factor económico. Ese factor lo sitúa como el elemento organizador cuyo nombre lleva la letra de palabras que expresan la realidad de estas iniciativas y es el motor de la actividad económica, se trata del Factor C. Este representa lo siguiente: compañerismo, cooperación, comunidad, compartir, comunión, colectividad y carisma. Explica el sociólogo que este factor es sustancial para concebir una nueva racionalidad económica pues implica que debemos hacerla juntos, en cooperación, en unión y en colectividad siendo estas características la condición para hacer una economía distinta (Razeto, 1997).

El sociólogo uruguayo Pablo Guerra, en su libro Socioeconomía de la solidaridad: una teoría para dar cuenta de las experiencias sociales y económicas alternativas (2014) realiza una profunda investigación desde la antropología, la economía y la sociología para refutar el carácter egoísta, individualista y competitivo del ser humano que descansan en las ideas liberales y económicas actuales. Como resultado de sus investigaciones, Guerra (2014) señala que lo distintivo y definitorio de la economía solidaria es que los recursos productivos, bienes o servicios producidos se asignan y se distribuyen "no solamente por medio de las relaciones de intercambio valoradas monetariamente (como sucede en el sector más propiamente capitalista), sino también mediante otras relaciones económicas que permiten una mayor integración social" (p. 36).

Por otra parte, Paul Singer, austriaco radicado en Brasil desde los 8 años, señala que la economía solidaria surge como un modo de producción y distribución alternativo al capitalismo, que es creado y recreado por los que se encuentran o temen ser marginados por el mercado de trabajo (Singer, 2007, p. 61). No obstante, Luiz Inácio Gaiger, sociólogo brasileño, advierte que aún no podemos concluir firmemente que el modo de producción y distribución en la economía solidaria es de carácter alternativo, pues crece y se sostiene dentro de una sociedad periférica, pero capitalista. Gaiger debate que más que "alternativas", las formas de la economía solidaria serían parte diferenciadas pero subordinadas a los modos de producción capitalista (Coraggio, 2007, p. 25). Además, reafirma que la economía solidaria se constituye por iniciativas populares de generación de trabajo y renta basada en la libre asociación de trabajadores y en los principios de autogestión y cooperación (UNIRCOOP, 2007, p. 12).

Finalmente, tomamos en consideración la Carta de Principios de la Economía Solidaria de la Red de Redes de Economía Alternativa y Solidaria (REAS) publicada en mayo de 2011 donde se definió que la economía solidaria es un enfoque de la actividad económica que tiene en cuenta a las personas, el medio ambiente y el desarrollo sostenible y sustentable, como referencia prioritaria, por encima de otros intereses. Además, enmarca la economía solidaria en la tradición de la economía social con la pretensión de incorporar a la gestión de la actividad económica, los valores universales que deben regir la sociedad y las relaciones entre toda la ciudadanía: equidad, justicia, fraternidad económica, solidaridad social y democracia directa.

De acuerdo con los conceptos definidos anteriormente, podemos establecer que en el ordenamiento jurídico actual en Puerto Rico contamos con cuatro tipos de organizaciones vinculadas a la economía social. Estos son: Cooperativas (COOP), Organizaciones Sin Fines de Lucro (OSFL), Corporaciones Especiales Propiedad de Trabajadores (PT's) y Empresas Sociales, constituidas por las Corporaciones de Beneficio Social (Corporación B) y Compañías de Responsabilidad Limitada con Fin Social (conocidas por sus siglas en inglés como L3C). A continuación, se presenta el marco legal y las estadísticas de cada una de ellas. 


\section{MARCO LEGAL E INSTITUCIONAL DE LAS ENTIDADES VINCULADAS A LA ECONOMÍA SOCIAL EN PUERTO RICO}

Como hemos mencionado anteriormente, el concepto de ESS es reciente en Puerto Rico. Por consiguiente, no existe una ley marco que agrupe o todos los emprendimientos asociados a la economía social y solidaria. En cambio, sí existe un marco legal para algunas de las entidades de la economía social como lo son las COOP, las OSFL, las PT's, Corporaciones B y las L3C.

Al igual que en la mayoría de los países, las cooperativas representan en Puerto Rico las organizaciones más identificadas con el concepto de economía social. Desde el surgimiento de la primera Sociedad de Socorro Mutuo Los Amigos del Bien Público en 1873 se han reconocido como asociaciones económicas sin interés de lucro en las cuales se practica la autogestión mediante una gestión democrática y participativa (Rosado, 2018).

En Puerto Rico existen tres leyes que agrupan las sociedades cooperativas, estas son: a) Ley General de Sociedades Cooperativas de Puerto Rico, Ley 239 de 1 de septiembre de 2004, b) Ley de Sociedades Cooperativas de Ahorro y Crédito, Ley 255 de 28 de octubre de 2002, según enmendada y, c) Ley especial de Cooperativas Juveniles, Ley 220 de 28 de octubre de 2002. De acuerdo con la Ley 239/2004, las cooperativas son personas jurídicas privadas de interés social, fundadas en la solidaridad y el esfuerzo propio para realizar actividades económico-sociales, con el propósito de satisfacer necesidades individuales y colectivas, sin ánimo de lucro. No obstante, en el caso de las cooperativas, a diferencia de otras organizaciones sin fines de lucro, la Ley 239/2004, permite la distribución de beneficios entre los asociados a base del patrocinio y capital aportado.

Las cooperativas que se incorporan bajo la Ley 239/2004 se les conoce como cooperativas de tipos diversos. Estas pueden ser de trabajo asociado, de consumo, de vivienda, comerciales o mixtas. En la actualidad están incorporadas 138 cooperativas de tipos diversos, 572 cooperativas juveniles y 111 cooperativas de ahorro y crédito. Según la Corporación Pública para la Supervisión y Seguro de Cooperativas de Puerto Rico (2018), las cooperativas en su totalidad asocian aproximadamente un millón de personas y crean más de 4.000 puestos de trabajo o empleos directos.

Las instituciones gubernamentales que fomentan y supervisan las cooperativas son: a) Comisión de Desarrollo Cooperativo de Puerto Rico (CDCOOP) encargada del fomento e incorporación de las cooperativas, b) el Instituto de Cooperativismo de la Universidad de Puerto Rico (ICOOP) que ofrece un grado de maestría en Gestión y Desarrollo de Cooperativas y Organizaciones Solidarias, además, ofrece cursos cortos a líderes cooperativistas, así como también brinda acompañamiento técnico-empresarial y filosófico a emprendimientos a través de su Programa de Incubadora y, c) la Corporación Pública para la Supervisión y Seguro de las Cooperativas de Puerto Rico (COSSEC) encargada de asegurar cooperativas financieras y fiscalizar a todo tipo de cooperativas en Puerto Rico. Por otro lado, en el año 2002 se creó el Fondo de Inversión de Desarrollo Cooperativo (FIDECOOP). Esta entidad es una organización sin fines de lucro formada por un acuerdo entre el movimiento cooperativo y el gobierno. E1 propósito del Fondo es financiar las inversiones de capital que se requieren para el desarrollo de nuevas empresas cooperativas.

La segunda entidad en Puerto Rico asociada a la economía social son OSFL. Estas son definidas por el Departamento de Estado del Gobierno de Puerto Rico de la siguiente manera: "...corporaciones domésticas o foráneas en que los ingresos obtenidos de su gestión se utilizan para promover los fines de la propia corporación y no para beneficiar económicamente a los miembros de dicha entidad a través de la repartición de ganancias". Las OSFL son regidas por 
la Ley General de Corporaciones de Puerto Rico, Ley Núm. 164 de 16 de diciembre de 2009. En ella se establecen unas responsabilidades que deben cumplir las OSFL como cualquier otra corporación.

Son corporaciones sin autoridad de emitir acciones de capital. Los sobrantes, si alguno, no pueden distribuirse entre sus miembros, directores $\mathrm{u}$ oficiales. Cualquier sobrante con el que cuente la entidad, luego de cubrir sus gastos operacionales, deberá retener y reinvertir en actividades compatibles con la misión para la cual se creó la organización. Pueden realizar las mismas actividades o negocios lícitos que una corporación con fines de lucro. Según Estudios Técnicos Inc. (2015) entre las clases de OSFL encontramos: servicios sociales, servicios legales, servicios educativos, servicios de salud, arte y cultura, servicios de recreación y deportes, servicios de vivienda, servicios ambientales, desarrollo económico, donativos, actividades internacionales, servicios religiosos, servicios institucionales y otros servicios. Los fondos provienen de diversas fuentes mediante personas naturales o jurídicas solidarias o filantrópicas o a través de actividades de recaudación de fondos.

En Puerto Rico hay unas 11.570 organizaciones sin fines de lucro que ofrecen servicios anualmente a más de 700.000 personas en la Isla. El sector produjo un total de 150.410 empleos a tiempo completo, lo que equivale al 16 por cien del empleo total del país. La nómina se estima en \$2,2 mil millones, en el cual se reflejan \$971 millones en las OSFL que dedican servicios sociales, \$965 millones en el sector de la salud y \$258 millones en el renglón de la educación. Al contabilizar este y otras aportaciones del sector se estima que su impacto representa alrededor de seis puntos seis por ciento (6,6 por cien) al Producto Nacional Bruto (PNB). Entre las fuentes de fondos de las corporaciones sin fines de lucro podemos mencionar: donativos de individuos (43,3 por cien), actividades de recaudación de fondos (41,8 por cien), donativo estatales, municipales o legislativos ( 38,0 por cien) y programas autosostenibles $(31,3$ por cien) (Estudios Técnicos Inc., 2015).

La tercera entidad con características de la economía social son las PT's. Estas corporaciones surgieron con el propósito de combatir el desempleo utilizando como referente las experiencias cooperativas en Puerto Rico, EE. UU. y Mondragón. En la exposición de motivos de la ley, que autorizó la organización de PT's (Ley 74 de 29 de agosto de 1990), expresó que la Asamblea Legislativa está comprometida a crear en Puerto Rico "instrumentos que redunden en la retención de empleos existentes, en la creación de nuevos empleos, particularmente de empleos que tengan raíces locales y en la creación de mecanismos que estimulen el ahorro y la inversión en los medios de producción del país. Las PT's representan un novedoso esquema corporativo que combina aspectos de una corporación tradicional con aspectos cooperativistas. Son corporaciones con fines de lucro, aunque la Ley permite que se conviertan en SFL a tono con la visión solidaria y colectiva. Para el año 2009 se aprobó una nueva Ley General de Corporaciones en Puerto Rico (Ley 164/2009) en la cual se incorporaron las PT's.

Las PT's se crearon para estimular la creación de empresas cuyos dueños sean sus trabajadores. En esta forma jurídica todo empleado tiene la oportunidad de ser dueño y todo dueño tiene que ser trabajador de la empresa. Los trabajadores dueños son considerados como trabajadores por cuenta propia para efectos de las leyes laborales. Los valores y principios son similares a los de las cooperativas como la gestión democrática y participativa (cada trabajador tiene derecho a un voto), autonomía de gestión, el apoderamiento de los trabajadores, la toma de decisiones colectivas, la distribución de los recursos económicos y el desarrollo de valores comunitarios y de solidaridad. Para finales de la década de 1990 se habían creado un total de 74 Corporaciones Especiales Propiedad de Trabajadores (Flores, 1999). En la actualidad, lamentablemente quedan menos de una docena de PT's en Puerto Rico. 
Finalmente, en el año 2015 se aprobó la Ley para crear las figuras de la Corporación de Beneficio Social y la Compañía de Responsabilidad Limitada con Fin Social, Ley Núm. 233 de 22 de diciembre de 2015. Como anteriormente mencionamos las Corporaciones B y las L3C pueden ser consideradas empresas sociales desde una visión amplia como iniciativas comerciales con un enfoque de negocio orientado a la misión social.

La exposición de motivos de dicha Ley 233/2015 expresa que por el arraigo que está teniendo el empresarismo social ha representado una tensión entre lo que podría llamarse la misión social de las empresas y el mandato corporativo de maximizar el valor de la inversión de los accionistas. Por ello, era necesario legislar para que una corporación o compañía pudiera tener entre sus propósitos el atender un fin social (Rosado, 2018).

Una Corporación B se define como una organización con fines de lucro, que puede emitir valores y acciones de capital, cuya misión y propósitos están dirigidos a fomentar el beneficio público general. Se entiende por beneficio público general un impacto positivo sustancial sobre la sociedad o el ambiente, que pueda ser medible y evaluado bajo estándares independientes, a través de actividades que promueven beneficios públicos que son definidos en la Ley. Mientras que L3C se organiza con propósito de negocio que satisface, y es operada en todo momento exclusivamente con fines religiosos, caritativos, científicos, literarios o educativos, o para fomentar la competencia deportiva amateur (no profesional) nacional o internacional, o para la prevención de crueldad hacia niños o animales. De manera que la creación de capital o la apreciación de propiedad no puede ser un propósito fundamental de la Compañía L3C (Ley 233/2015). Las Corporaciones B y las Compañías L3C son de recién creación en Puerto Rico por lo que actualmente son pocas las incorporadas y activas.

Todas las OSFL, PT's, Corporaciones B y L3C se registran en el Departamento de Estado. A diferencia de las Cooperativas, no tienen una institución gubernamental que las regule. No obstante, las OSFL y las PT's deben someter un informe financiero anualmente al Departamento de Hacienda. Las corporaciones B y las L3C deben someter al Departamento de Estado una declaración en cuanto a la promoción y operación anual de la corporación sobre el beneficio público general establecido en el certificado de incorporación (Ley 233/2015).

\section{METODOLOGÍA}

El perfil de emprendimientos de la ESS es una investigación aplicada de tipo descriptiva y de naturaleza cualitativa. Los participantes en la investigación fueron personas que representaban entidades de la economía social y solidarias. Se les solicitó que cumplimentaran el cuestionario de forma voluntaria y se les informó que tenían el derecho a no responder a alguna pregunta y de abstenerse o retirarse de la consulta sin ninguna penalidad. Respondieron al cuestionario 72 personas, sin embargo, para poder lograr un perfil nacional se excluyeron las respuestas de las entidades internacionales. Por consiguiente, fueron 68 cuestionarios los considerados para plasmar este perfil.

La técnica utilizada para recopilar datos fue un cuestionario sometido a revisión y autorización del Comité Institucional para la Protección de los Seres Humanos en la Investigación (CIPSHI), comité institucional de revisión o Institutional Review Board (IRB) de la Universidad de Puerto Rico, Recinto de Río Piedras. Además, se preparó una hoja de consentimiento informado que contenía la descripción y los objetivos de la investigación, los riesgos y beneficios, los métodos de confidencialidad, la forma en que se divulgan los hallazgos y los derechos por colaborar en la recopilación de datos.

El cuestionario contenía veinte (20) preguntas, cinco(5) de ellas abiertas, dirigidas a obtener información sobre: a) la misión social, ambiental o comunitaria; b) la actividad socioeconómica; 
c) las características como organización de la economía social y solidaria; d) el medio o método de medición del impacto social y, e) los retos o dificultades para el logro de su misión u objetivos sociales y económicos. El cuestionario fue construido en la plataforma Google Form.

Se brindaron varias alternativas para que los participantes pudieran cumplimentar el cuestionario. Primero, el cuestionario fue enviado por correo electrónico a 150 organizaciones previamente identificadas. En segundo lugar, se suministró el día en que se llevó a cabo la actividad asistido por una persona adscrita a la investigación. Por último, estuvo disponible 15 días después del encuentro para lograr una mayor recopilación de datos.

Para la obtención de los datos en el encuentro se orientó a los participantes sobre la investigación y se le requirió la firma de la hoja de consentimiento informado. Al firmar la persona aceptaba participar voluntariamente en el estudio, afirmaba que era mayor de edad y aceptaba que tenía la autoridad legal o delegada para ofrecer información sobre la entidad. Se les ofreció copia de este documento. Luego de este trámite, comenzaron a responder el cuestionario. Por último, como método de protección a la privacidad y a la confidencialidad de los participantes, se les notificó que el investigador principal es la única persona que tiene acceso a los cuestionarios cumplimentados. La información se presenta de forma agregada en este informe para evitar la identificación de los participantes o la entidad que representan.

Para analizar las preguntas abiertas del cuestionario utilizamos la técnica de análisis de contenido. Bardin (1991) propone la siguiente definición: "Un conjunto de técnicas de análisis de las comunicaciones utilizando procedimientos sistemáticos y objetivos de descripción del contenido de los mensajes". Con esta técnica buscamos la significación del mensaje en el discurso de los participantes mediante la formulación de inferencias que surgen de la identificación sistemática de características dentro del contenido.

El análisis de contenido se desarrolló en cuatro fases: a) pre-análisis, b) definición de las unidades de análisis, c) códigos de clasificación y, d) desarrollo de categorías. En la fase de pre-análisis se sustrajo los datos de la plataforma digital y se transfirió la información a unas tablas preparadas para cada una de las preguntas abiertas. En la fase de definición de las unidades de análisis se seleccionaron los trozos de contenido sobre los cuales se elaboró la discusión. Luego, se establecieron las reglas de análisis para codificar. Finalmente, se establecieron unas categorías donde se agrupó o se vinculó la información. En algunas de las preguntas se realizó un proceso de categorización que respondió a método inductivo. En otras, se clasificaron de acuerdo a los criterios establecidos.

La presentación de algunos de los datos del perfil se hace a través de ilustraciones gráficas que prepara de forma automática la plataforma de Google Form. En las mismas se presentan el promedio o valor "central" calculado entre un conjunto de números derivados de las respuestas a las preguntas. Los datos de las preguntas abiertas se presentan en tablas o listas en la cual se muestra el contenido manifiesto (respuestas) de forma directa, agrupada o relacionada a las categorías de análisis establecidas.

\section{RESULTADOS Y DISCUSIÓN}

A continuación, se presentan los resultados de la investigación de acuerdo al cuestionario y las categorías utilizadas para el análisis de las preguntas abiertas.

La primera pregunta sociodemográfica que realizamos fue sobre el tipo de entidad o personalidad jurídica de acuerdo con el ordenamiento actual en Puerto Rico. Como era de esperarse, por la proporción de este tipo de personalidad jurídica con respecto a las demás, el cuarenta y cinco por cien fueron organizaciones sin fines de lucro. Al ser el grupo mayor, 
podemos inferir que los resultados de las categorías de análisis próximas a discutir como: actividad económica, población a la que ofrecen servicios y métodos de medición del impacto social provienen de las OSFL.

Resulta significativo que el veintinueve por cien de los emprendimientos participantes del encuentro tuvieran otra personalidad jurídica distinta a las formas tradicionales de las organizaciones de la ESS. Este dato nos resulta interesante porque nos puede conducir a dos cambios. El primero, abre a la discusión acerca de qué otras formas, sociedades o asociaciones podemos crear en nuestro ordenamiento jurídico cimentadas en la economía social y solidaria. En otras palabras, nos invitan repensar la formulación de una política pública que incluya una diversidad de personalidades jurídicas. El segundo camino nos lleva a que podrían ser entidades dedicadas al apoyo, promoción, desarrollo o integración de los emprendimientos de la economía social y solidaria en Puerto Rico. Estas organizaciones podrían ser universidades o centros de estudio e investigación, movimientos sociales, entre otras. También encontramos artesanos y comerciantes individuales haciendo negocios bajo un nombre comercial. Aunque estos emprendimientos son individuales, su producto puede cumplir con algunas de las características de las organizaciones solidarias como el principio de sostenibilidad ambiental o compromiso con el entorno. Cualquiera de las dos vías de interpretación resulta ser un porciento significativo que debe ser definido.

El tercer sector con mayor participación fueron las sociedades cooperativas con el diecisiete por cien. Este dato visibiliza que el pensamiento y la práctica cooperativista, a pesar de ser la personalidad jurídica más antigua de las presentadas en el cuestionario, continúa teniendo relevancia como organización de la economía social y solidaria en el país. La figura 1 presenta la proporción de entidades.

\begin{tabular}{|l|l|}
\hline & FIGURA 1 \\
\hline $\begin{array}{l}\text { Tipo de entidad (personalidad juridica) } \\
68 \& \text { nbsp;respuestas }\end{array}$ & $\begin{array}{l}\text { Cooperativa (COOP) } \\
\text { Corporación Propiedad de Trabajadores } \\
\text { (PT) }\end{array}$ \\
Corporación de Beneficio Social (BCorp) \\
o Responsabilidad Limitada (LC3) \\
Organización Sin Fines de Lucro \\
(OSFL) \\
Fuente: Elaboración propia.
\end{tabular}

Se le hizo la pregunta abierta a los participantes sobre la misión social, ambiental o comunitaria que tienen los emprendimientos. La misión es una expresión que define la razón de ser de una organización, empresa o institución. En las respuestas a la pregunta observamos en la mayoría de los participantes, definen su misión social, ambiental o comunitaria. Sin embargo, identificamos también, en algunos de ellos, que se menciona la actividad socioeconómica como la misión del emprendimiento. En este caso, el motivo o propósito por el cual se lleva a cabo el emprendimiento solidario. Consideramos que es importante tener claro y presente la misión pues son la guía que mantienen a los emprendimientos sociales enfocados en que la actividad económica debe estar al servicio de las personas. También sirve para no confundir fines y propósitos sociales del emprendimiento con el medio empresarial mediante el cual se llega al logro de estos. 
Se les preguntó también a los participantes sobre la actividad socioeconómica que realizan para el logro de los objetivos del emprendimiento. La intención de esta pregunta era que los participantes pudieran expresar brevemente la actividad socioeconómica que realizan y las áreas o sectores más comunes. Las actividades socioeconómicas de más frecuencia entre los emprendimientos están relacionadas a los servicios en educación y a la producción y venta de productos en el sector agrícola. En la tabla 1 se detallan las respuestas sobre la actividad socioeconómica de los emprendimientos.

Se les solicitó a los participantes en una pregunta abierta que mencionaran al menos dos características del emprendimiento que les hiciera pertenecer a la economía social y solidaria. Observamos que muchas de las características mencionadas aluden de forma directa o indirecta a los principios de la economía solidaria o con las características de las entidades pertenecientes a la economía social. También mencionaron la personalidad jurídica del emprendimiento como ser asociación comunitaria, organización sin fin de lucro o cooperativa. No obstante, otras de las respuestas estaban relacionadas a la actividad de producción de bienes o servicios que ofrecen, o con la meta explícita de beneficiar a un grupo o comunidad.

\begin{tabular}{|c|c|c|}
\hline \multicolumn{3}{|c|}{$\begin{array}{l}\text { TABLA 1. ACTIVIDAD SOCIOECONÓMICA DE LOS EMPRENDIMIENTOS } \\
\text { SOLIDARIOS }\end{array}$} \\
\hline Cantidad & Actividad & Área/ Sector relacionado \\
\hline 15 & $\begin{array}{l}\text { - Educación formal } \\
\text { - Seminarios y talleres en temas } \\
\text { de: agricultura, economía social } \\
\text { y solidaria, asuntos ambientales, } \\
\text { agroecología, financiera, otros } \\
\text { temas. } \\
\text { - Movilización Social }\end{array}$ & Educación/ Cultura \\
\hline 7 & $\begin{array}{l}\text { - Incubadora de microempresas, } \\
\text { cooperativas } \\
\text { - Servicios de Asesoría } \\
\text { - Redes }\end{array}$ & Asesoría Empresarial \\
\hline 2 & $\begin{array}{l}\text { - Servicios financieros (ahorro y } \\
\text { crédito) } \\
\text { - Seguros }\end{array}$ & Finanzas \\
\hline 5 & $\begin{array}{l}\text { - Composta, vegetales, hierbas } \\
\text { medicinales, Semillas }\end{array}$ & Producción Agrícola \\
\hline 3 & - Alimento, ropa, calzado & Producción de otros productos \\
\hline 5 & - Atención médica & Salud \\
\hline 5 & - Diseño, legales, consultoría & Servicios profesionales \\
\hline 5 & $\begin{array}{l}\text { - Recorridos acuáticos y } \\
\text { terrestres, ecoturismo, }\end{array}$ & Turismo \\
\hline 9 & $\begin{array}{l}\text { - Leche, huevos, carne, vegetales, } \\
\text { café, plantas }\end{array}$ & Venta productos agrícolas \\
\hline 9 & $\begin{array}{l}\text { - Artesanías, productos de } \\
\text { comercio justo }\end{array}$ & Venta/ alquiler de otros productos \\
\hline $\mathrm{N}=65$ & - Total & \\
\hline
\end{tabular}

Fuente: Elaboración propia. 
Uno de los objetivos prácticos de la economía solidaria es rescatar las diversas experiencias de hacer economía en sus diversas fases como la producción, la distribución, el consumo y la acumulación. En el caso de Puerto Rico es importante conocer en qué fase de la economía participan mayormente las organizaciones sociales y solidarias. Según los resultados del estudio el sesenta y cuatro por cien de los emprendimientos se dedican a la actividad económica de producción de bienes y servicios. De estos servicios, el cuarenta y siete por cien son profesionales o técnicos que corresponde a la base de la economía nacional. La otra actividad económica de importancia es la distribución o comercialización de bienes con un dieciséis por cien. La figura 2 presenta las actividades económicas que realizan las entidades.

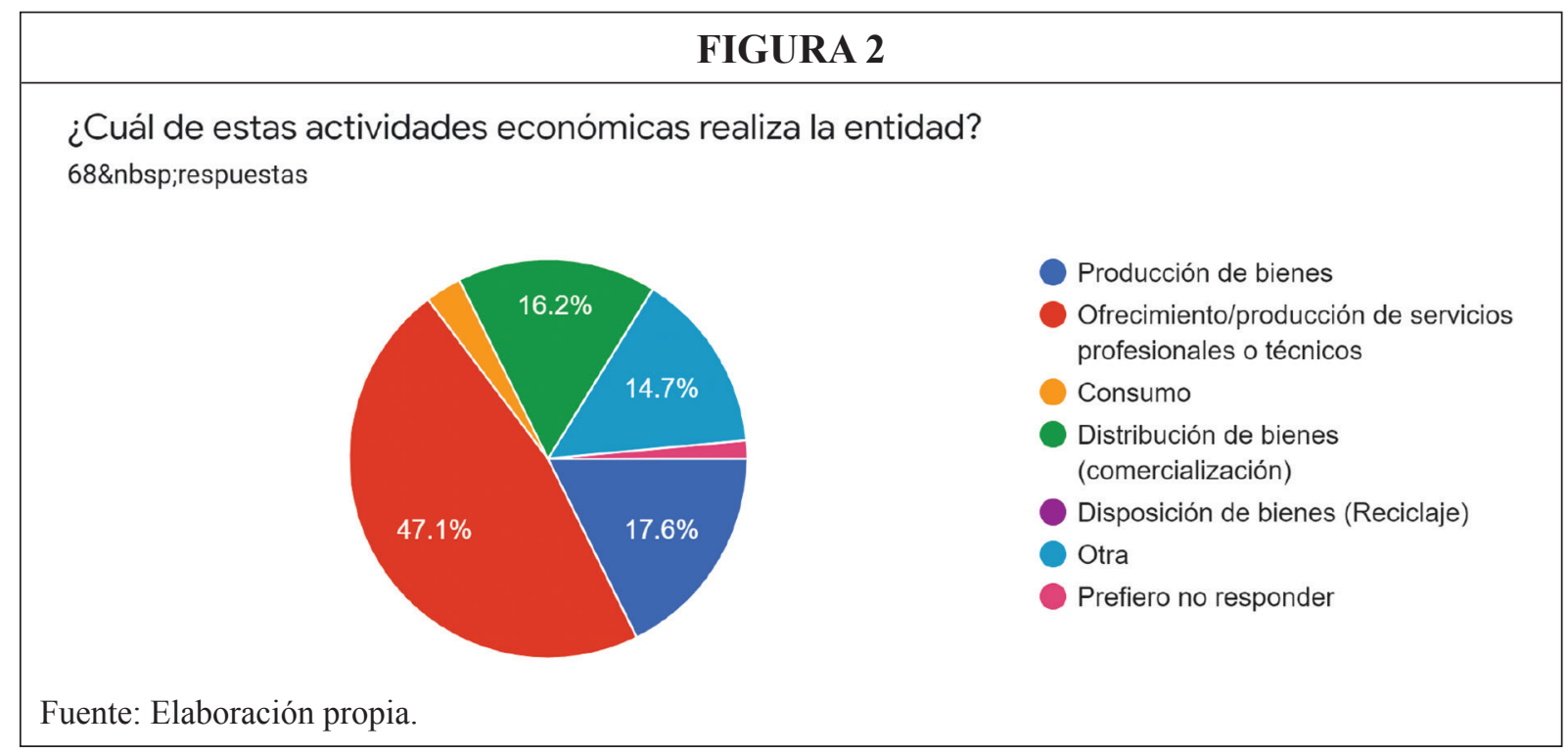

De acuerdo con las respuestas de los emprendimientos participantes pertenecen a una gran diversidad de industrias de acuerdo con el CIIU. La industria más importante es la agricultura, ganadería, silvicultura y pesca con un dieciséis por cien, seguido por industrias de enseñanza con un trece por cien y actividades profesionales, científicas y técnicas, con un doce por cien. Las otras dos industrias de importancia a las que pertenecen los emprendimientos son la manufacturera y comercio al por mayor y al detal, ambas con un nueve por cien. La figura 3 muestra distribución según la CIIU.

\begin{tabular}{|l|l|}
\hline & FIGURA 3 \\
\hline $\begin{array}{l}\text { Según la Clasificación Industrial Internacional Uniforme (CIIU) ¿A qué industria pertenece la } \\
\text { entidad? } \\
66 \text { respuestas }\end{array}$ & $\begin{array}{l}\text { Agricultura, ganadería, sivicultura y pe... } \\
\text { Industrias manufactureras } \\
\text { Suministro de electricidad o agua }\end{array}$ \\
$\begin{array}{l}\text { Construcción } \\
\text { Comercio al por mayor y al por menor } \\
\text { Transporte y almacenamiento } \\
\text { Actividades de alojamiento y de servic... } \\
\text { Información y comunicaciones }\end{array}$ & $\begin{array}{l}16,7 \% \\
\text { Fuente: Elaboración propia. }\end{array}$
\end{tabular}


La mayoría de los emprendimientos, un setenta y tres por cien, informaron que los servicios o productos de la entidad están dirigidos a la población en general. Los otros sectores de la población, que son importantes mencionar, son las comunidades desventajadas económicamente y las comunidades vulnerables o marginadas. Estás, en agregado, representan el diez por cien de la población que recibe servicios.

Se les preguntó a los participantes sobre los ingresos anuales generados por el emprendimiento con el propósito de clasificarlas dentro de las definiciones de las empresas establecidas por la Compañía de Comercio y Exportación de Puerto Rico. El Reglamento para la Certificación de Micro, Pequeñas y Medianas Empresas en el Programa de Reservas en las Compras del Gobierno del Estado Libre Asociado de Puerto Rico (Reglamento 8588 de 2015) define una microempresa como un negocio que genera un ingreso bruto menor de quinientos mil dólares $(\$ 500.000)$ cada año y posee 7 empleados o menos. Un pequeño comerciante significa un negocio que genera un ingreso bruto menor de tres millones de dólares $(\$ 3.000 .000)$ cada año y que posee veinticinco $(25)$ empleados o menos. En el caso de los comerciantes medianos, significa que el negocio genera un ingreso bruto menor a los diez Millones de dólares (\$10.000.000) cada año y posee cincuenta (50) empleados o menos. Para los propósitos de este perfil se considera una empresa grande aquella que tiene ingresos que superan los veinticinco millones de dólares $(\$ 25.000 .000)$.

Conforme con estas clasificaciones el setenta y dos por cien de los emprendimientos son considerados microempresas con ingresos menores a los $\$ 500.000$. El seis por cien son pequeñas empresas y el tres por cien son medianos comerciantes. Al unir estas tres clasificaciones tenemos que el ochenta y un por cien de los emprendimientos son definidos como Pymes. Solo un tres por cien de los emprendimientos son considerados como empresas grandes. Sin embargo, el 16,2 por cien decidieron no responder. La figura 4 presenta los ingresos de las entidades.

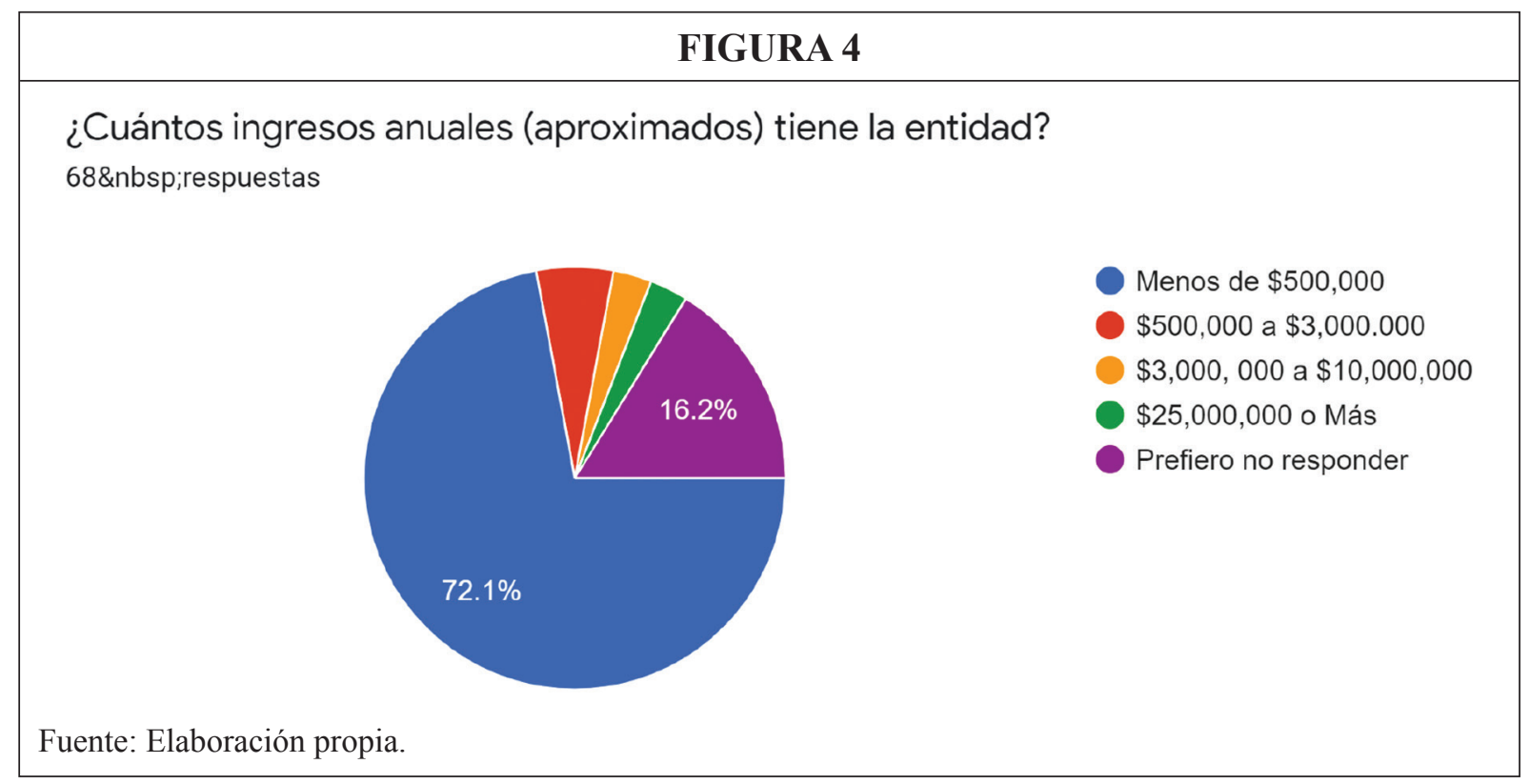

En el estudio de las Organizaciones Sin Fines de Lucro en Puerto Rico realizado en 2015, solo el treinta y un por cien de la OSFL tiene programas autosostenibles. Según los resultados de esta investigación, el sesenta y seis por cien de los emprendimientos tiene una fuente principal de ingresos propia que proviene de la venta de bienes y servicios. La segunda fuente de ingresos son los donativos de individuos o empresas con un treinta y tres por cien. Este dato es importante para los emprendimientos solidarios ya que no dependen de factores externos para su sostenibilidad. La figura 5 detalla la fuente de ingresos de los emprendimientos. 


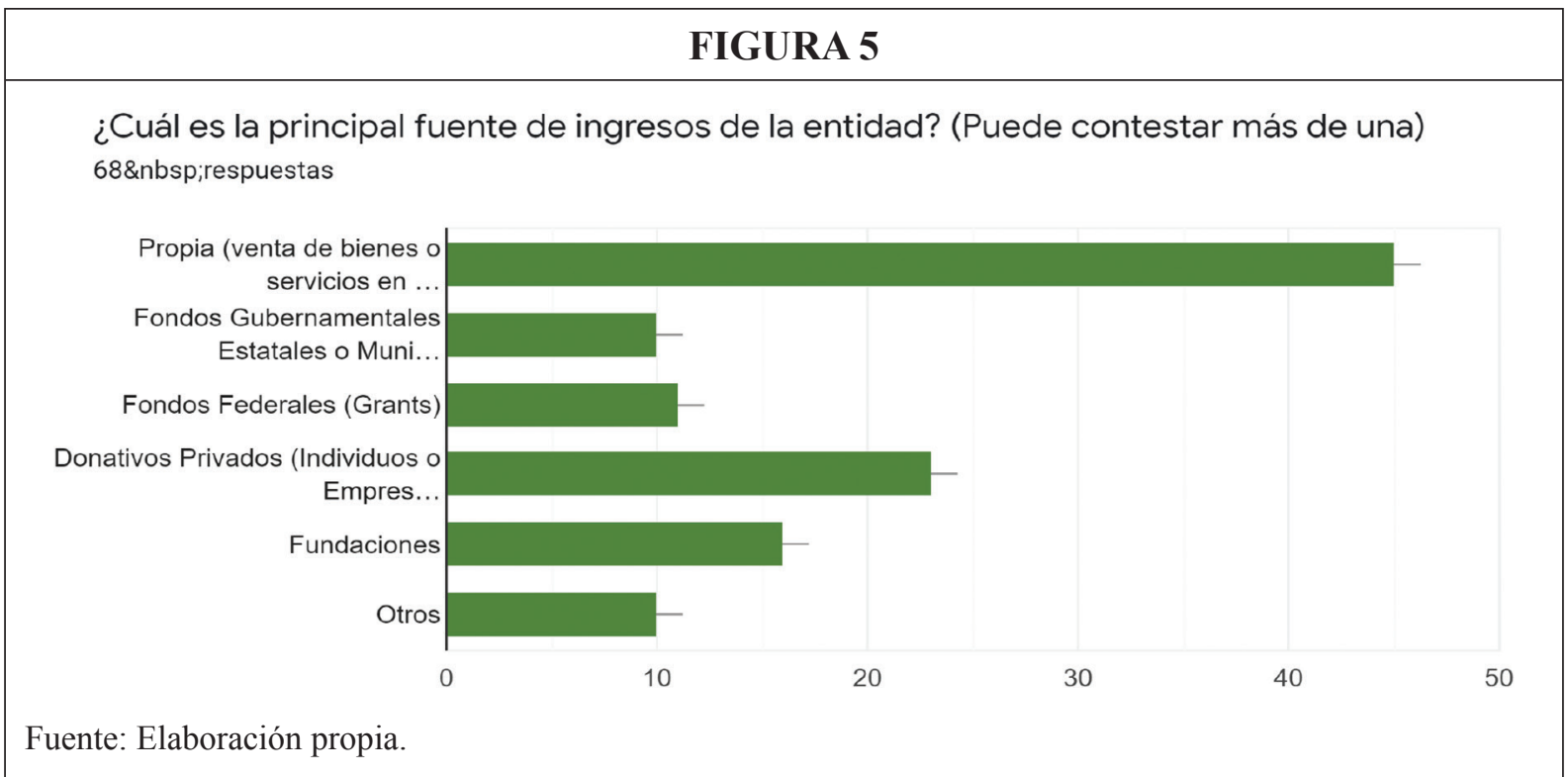

El asociativismo es una de las características de los emprendimientos sociales y solidarios. Según el cuestionario el sesenta por cien de los emprendimientos participantes son asociativos. También participaron emprendimientos individuales (10,3 por cien) y familiares (4,4 por cien).

Muchos de los emprendimientos sociales y solidarios son organizados por trabajadores que se asocian para producir o distribuir bienes y servicios en o fuera del mercado. De acuerdo con los resultados del estudio, casi la mitad, el cuarenta y nueve por cien de los emprendimientos participantes cuentan con un grupo de uno a siete trabajadores asociados. Solo un tres por cien de los emprendimientos tiene más de cincuenta trabajadores asociados. Mientras que el treinta y cinco por cien de los emprendimientos participantes no tiene ningún trabajador asociado.

Según los resultados, el sesenta por cien de los emprendimientos participantes tienen empleados asalariados. De estos, el cuarenta y un por cien tiene entre uno a siete empleados, el cuatro por cien entre ocho y veinticinco y el siete por cien tiene más de cincuenta. También el estudio reveló que el cuarenta y un por cien no tiene ningún empleado asalariado, probablemente emprendimientos que solo tienen trabajadores asociados.

Según el cuestionario el sesenta y uno por cien, casi dos terceras partes de los emprendimientos participantes, miden el impacto social, ambiental o comunitario de la actividad que realizan. Entendemos que este hecho se relaciona en gran medida a la elaboración de informes a las entidades que proveen financiamiento a los emprendimientos.

Según los resultados podemos decir que más de la mitad de los cuarenta y nueve emprendimientos que contestaron esta pregunta, el cincuenta y siete por cien mencionaron solo indicadores específicos para medir el impacto social. Solo seis de los emprendimientos que contestaron esta pregunta indicaron que utilizan un método formal para medir el impacto social. Algunos de los mencionados fueron, Key Performance Indicators, Cuestionario de B-Corp, Objetivos de Desarrollo Sostenible de la UNESCO y el Sistema de Acopio de Datos de Impacto Social (SADIS). Los otros dos emprendimientos han desarrollado métodos o instrumentos con indicadores cuantitativos y cualitativos. Otros emprendimientos mencionaron que utilizan métodos informales o técnicas de recolección de datos como: conversaciones, discusiones informales, grabaciones, entrevistas, cuestionarios, plantillas, censos y feedback de las redes.

La economía social y solidaria favorece la cooperación en lugar de la competencia, dentro y fuera de las organizaciones. Se busca la colaboración con otras entidades y organismos 
públicos y privados. Por esto es importante crear redes y trabajar de forma conjunta entre los diferentes actores de la Economía Social. Los emprendimientos participantes tienen alianzas con diversas organizaciones, particularmente con Organizaciones Sin Fines de Lucro (76,1 por cien), Empresas Privadas (46,3 por cien), Fundaciones (43,3 por cien) y Cooperativas (37,3 por cien). La figura 6 detalla las organizaciones con las que tienen alianza los emprendimientos.

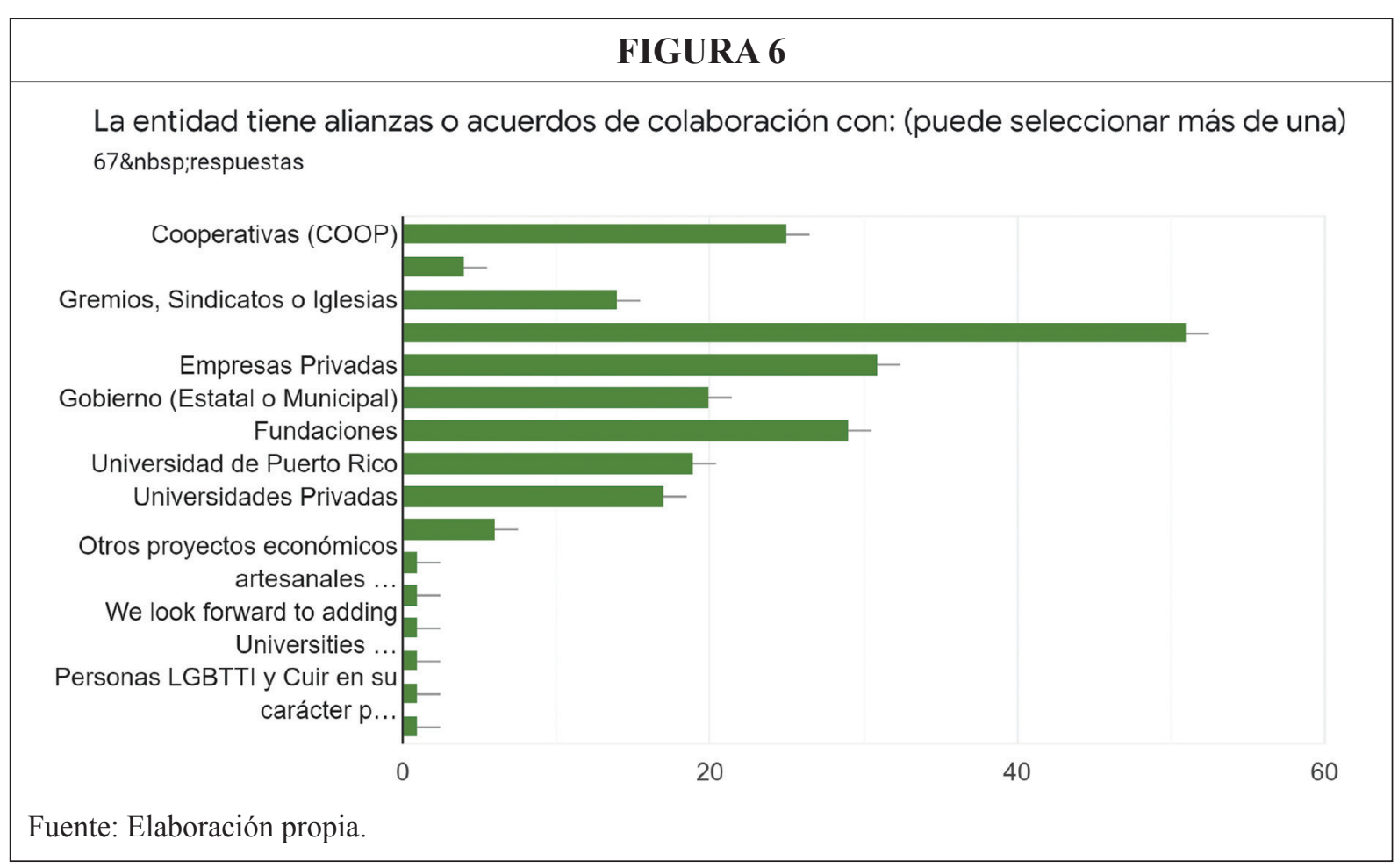

Por último, se indagó sobre retos o las dificultades que entienden los emprendimientos participantes para poder lograr su misión u objetivos sociales y económicos. Conforme a las contestaciones se establecieron las siguientes categorías de análisis: contexto, social, económico o empresarial. Por contexto nos referimos a situaciones externas a las organizaciones que impactan a los emprendimientos como ambientales, económicos o políticos. Las otras categorías se refieren a situaciones internas o propias de los emprendimientos. En término de contexto se identificaron las siguientes dificultades:

- Eventos naturales

- Recesión económica

- Estabilidad del sector económico

- Obstrucción política

- Burocracia gubernamental

- Regulación gubernamental

- Falta de colaboración gubernamental

Al interior de los emprendimientos, las mayores dificultades señaladas expresadas fueron en el aspecto económico asociado a la falta de capital, liquidez, financiamiento, inversiones y la dependencia de los presupuestos fiscales (entes financiadores). Otras dificultades mencionadas están relacionadas con aspectos empresariales como:

- Apoyo legal

- Aumento de producción 
- Capacitación

- Paga digna (salarios)

- Viabilidad

- Métricas (evaluación)

- Tecnología

- Mercadeo

- Materia Prima

- Facilidades Físicas

- Contabilidad

- Publicidad

- Conocimiento

- Contratos/clientes

- Cumplimiento trabajo administrativo

- Proceso organizativo

- Modelo de Negocio

- Falta de personal

- Mantener precio justo

- Falta de Redes y relaciones

- Necesidad de colaboración

Finalmente, los emprendimientos también indicaron tener dificultades de tipo social para cumplir con su misión relacionadas a la identidad, estructura social y falta de educación en la organización.

\section{CONCLUSIONES, RECOMENDACIONES Y LÍNEAS FUTURAS DE INVESTIGACIÓN}

Esta investigación recoge solamente la información de las entidades que asistieron al Primer Encuentro Internacional de Economía Social y Solidaria: Conectando experiencias en Puerto Rico. Por lo cual debemos establecer que no es una muestra representativa de todas las entidades que pueden ser consideradas como emprendimientos sociales y solidarios. No obstante, es un primer esfuerzo por caracterizar los emprendimientos y de vincular la conceptualización de la economía social y solidaria con el marco legal e institucional de las entidades existentes en Puerto Rico.

La información obtenida en esta investigación servirá para establecer un primer perfil de los emprendimientos solidarios y para que el Comité Timón de la Red de Economía Social y Solidaria PR, conformado en agosto de 2021, pueda articular un plan para apoyar y desarrollar la ESS en el país. Asimismo, será de gran utilidad para que el ICOOP pueda: a) colaborar en la creación de una política pública cónsona con la realidad de los emprendimientos; b) continuar con el análisis de los datos en los distintos programas de servicio y; c) proseguir en la construcción de la base nacional de datos de este sector.

Como planteamos en la introducción las OSFL son las entidades que predominan. Sin embargo, estas no recogen otras iniciativas que puedan estar asociadas a la ESS. En este perfil se demuestra que los emprendimientos que participaron en el estudio se identifican con las características de la economía social y los principios de la economía solidaria más allá de la no lucratividad como característica definitoria. En este sentido, el concepto de la ESS comienza a tener más presencia en la conciencia colectiva. Por esto recomendamos fortalecer la ESS en Puerto Rico mediante la creación de una ley marco que reconozca, promueva y apoye la ESS 
en todas sus manifestaciones. Además, defina o acoja los principios de la ESS y establezca las características de los emprendimientos sociales y solidarios reconocidos internacionalmente. Asimismo, el proyecto de ley debe tener como objetivos: a) el desarrollo de una economía con perspectiva en los derechos humanos y primando la dignidad de las personas, b) basada en la gestión democrática y participativa, c) centralizada en el trabajo, en el desarrollo local sustentable y sostenible y, d) cimentada en la solidaridad y la cooperación.

Concluimos también que la ley marco de la ESS debe reorganizar el marco jurídico actual. Por ejemplo, consideramos que las OSFL, las Corporaciones B, las Compañías L3C y las PT's no deben figurar en la Ley General de Corporaciones de Puerto Rico, Ley Núm. 164 de 16 de diciembre de 2009 puesto que, según vimos en el perfil, estas se identifican con la ESS. No obstante, para que puedan ser cónsonas con los principios de la ESS, estas entidades deben incluir una gestión democrática y participativa además de realizar un esfuerzo para la conservación y respeto del ambiente. La figura 7 presenta un ejemplo de lo que podría ser la estructura de la ley marco de ESS en Puerto Rico.

FIGURA 7. EJEMPLO DE LA ESTRUCTURA DE LA LEY MARCO PARA LA ESS EN PUERTO RICO

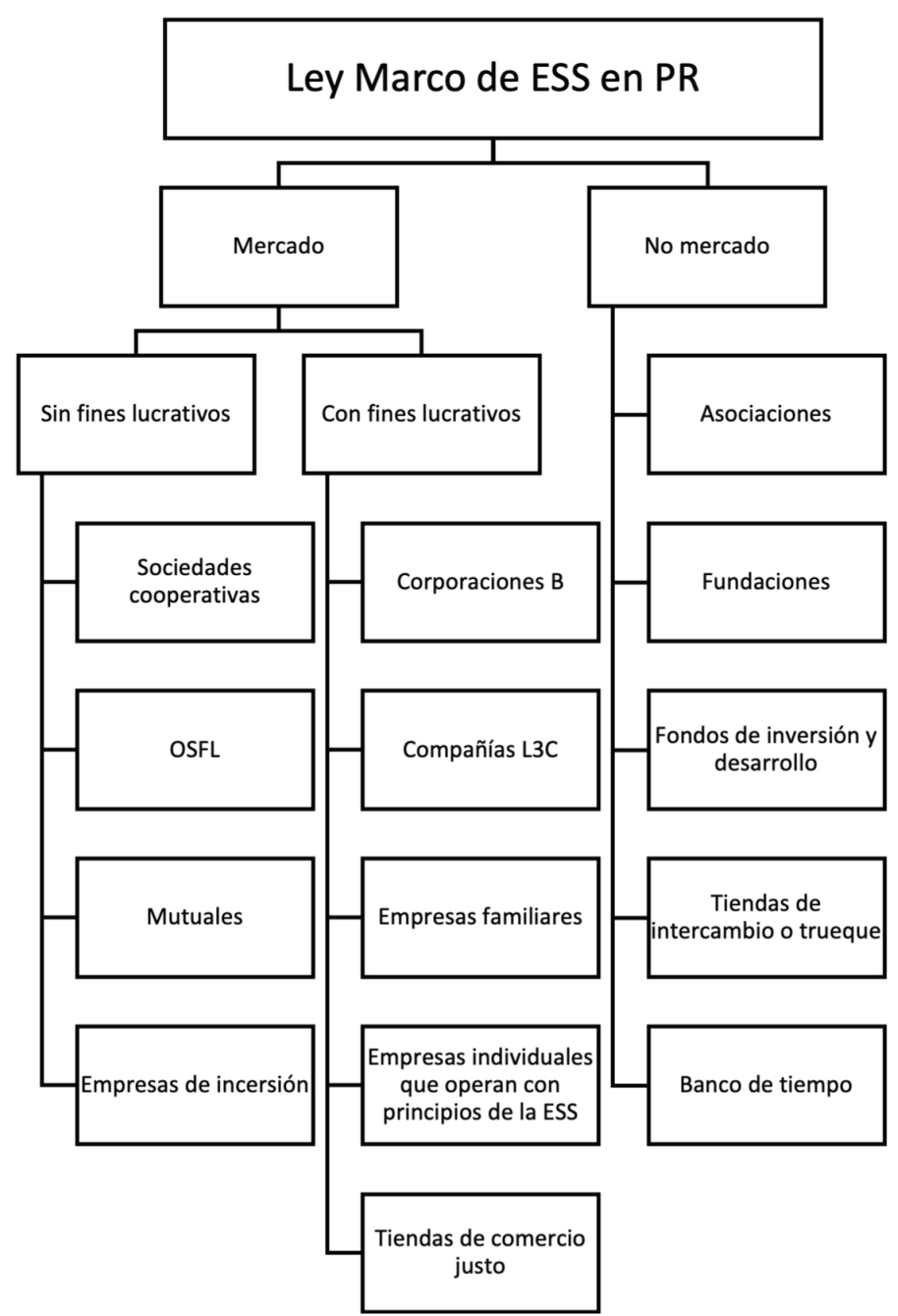

Fuente: Elaboración propia. 
Una vez que se establezca el marco legal de la ESS se podrá hacer un registro que recopile todos los emprendimientos sociales y solidarios. Esto servirá además a documentar y levantar datos estadísticos que ayuden a medir el impacto social y económico en el país. Mientras se construye este marco legal, recomendamos continuar recopilando información de otras iniciativas que nos ayuden a establecer un perfil más representativo y detallado de los emprendimientos sociales y solidarios en Puerto Rico.

Finalmente, a partir de este perfil, presentamos posibles líneas futuras de investigación:

1. Estudio sobre el funcionamiento interno de organizaciones y emprendimientos solidarios en Puerto Rico

2. Análisis de las lógicas socioeconómicas que rigen la operación de estas entidades y la aplicación de los principios solidarios

3. Descripción de la acción política de las organizaciones y emprendimientos solidarios

4. Relación estado, mercado y emprendimientos solidarios en Puerto Rico

5. Potencialidades de cambio social del sector solidario

6. Herramientas de medición del impacto social de los emprendimientos solidarios

\section{BIBLIOGRAFÍA}

Comité Económico y Social Europeo. (2017). Evolución reciente de la economía social en la Unión Europea. Estudio realizado por CIRIEC-International - Centre international de recherches et d'information sur l'économie publique, sociale et coopérative. http://www. ciriec.uliege.be/wp-content/uploads/2018/09/evol-recente-ES-UE-resume-es.pdf

Compañía de Comercio y Exportación de Puerto Rico. (2015). Reglamento para la Certificación de Micro, Pequeñas y Medianas Empresas en el Programa de Reservas en las Compras del Gobierno del Estado Libre Asociado de Puerto Rico. (Reglamento Núm. 8588). https:// transicion2016.pr.gov/Agencias/258/Informe por cien20de por cien20Reglamento por cien20y por cien20Normas/REGLAMENTO por cien20CERTIFICACION por cien20MICRO, por cien20PEQUE por cienC3 por cien91A por cien20Y por cien20MED por cien20EMPRESAS por cien208588.pdf

Coraggio, L. (Org.). (2007). La economía social desde la periferia contribuciones latinoamericanas. Editorial Altamira.

Estudios Técnicos, Inc. (2015). Estudio de las Organizaciones Sin Fines de Lucro en Puerto Rico. Resumen de hallazgos sobresalientes. https://unitedwaypr.org/wp-content/ uploads/2019/02/halllazgos-sobresalientes-osfl-presidentes.pdf

Guerra, P (2014). Socioeconomía de la solidaridad: Una teoría para dar cuenta de las experiencias sociales y económicas alternativas. Editorial de la Universidad Cooperativa de Colombia. https://doi.org/10.16925/9789587600308

Flores, A. (1999). Las corporaciones especiales propiedad de trabajadores: de la alienación al apoderamiento y su rol en el desarrollo de comunidades de escasos recursos económicos en Puerto Rico. [Tesis de Maestría no publicada]. Universidad de Puerto Rico.

Laville, J. (Org.). (2004). Los aportes y límites de la economía social. Economía social y solidaria una visión europea. Editorial Altamira.

Ley General de Corporaciones de Puerto Rico, Ley Núm. 164 de 16 de diciembre de 2009, según enmendada. https://bvirtualogp.pr.gov/ogp/Bvirtual/leyesreferencia/PDF/ Corporaciones por cien20Privadas/164-2009/164-2009.pdf 
Ley General de Sociedades Cooperativas de Puerto Rico de 2004, Ley 239 de 1 de septiembre de 2004, según enmendada. https://bvirtualogp.pr.gov/ogp/Bvirtual/leyesreferencia/ PDF/Cooperativas/239-2004/239-2004.pdf

Ley para crear las figuras de la Corporación de Beneficio Social y la Compañía de Responsabilidad Limitada con Fin Social, Ley Núm. 233 de 22 de diciembre de 2015. https://bvirtualogp. pr.gov/ogp/Bvirtual/leyesreferencia/PDF/2/0233-2015.pdf

Organización de las Naciones Unidas. (2016). Sistema de Cuentas Nacionales 2008. https:// unstats.un.org/unsd/nationalaccount/docs/SNA2008Spanish.pdf

Pérez de Mendiguren, J., Etxezarreta, E. \& Guridi, L. (2008). ¿De qué hablamos cuando hablamos de economía social y solidaria? Concepto y nociones afines. [Conferencia]. XI Jornadas de Economía Crítica. https://www.economiasolidaria.org/biblioteca/de-quehablamos-cuando-hablamos-de-economia-social-y-solidaria-concepto-y-nociones

Razeto, L. (2007). La economía de solidaridad: concepto, realidad y proyecto. Economía social desde la periferia contribuciones latinoamericanas. Ediciones Altamira.

Razeto, L. (2010). Curso Economía Solidaria. Universidad Virtual.

Red de Redes de Economía Alternativa y Solidaria. (2011). Carta de Principios de la Economía Solidaria. http://www.economiasolidaria.org/files/CARTA_ECONOMIA_ SOLIDARIA_REAS.pd

Rosado, E. (2018). La Economía Social en Puerto Rico. Anuario Iberoamericano de la Economía Social. 3, 2018 C CIRIEC-España, Centro Internacional de Investigación e Información sobre la Economía Pública, Social y Cooperativa. http://www.oibescoop. org/wp-content/uploads/Anuario-OIBESCOOP-2019-def.pdf

Salamon, L. \& Anheier, H. (1997). The Third World's Third Sector in Comparative Perspective. Working Papers of the Johns Hopkins Comparative Nonprofit Sector Project, 24, edited by Lester M. Salamon and Helmut K. Anheier. The Johns Hopkins Institute for Policy Studies, 1997. https://www.sociedadenaccion.cl/wp-content/uploads/2015/06/SalamonL.-Anheier-H.-1997.-The-Third-World por cienE2 por cien80 por cien99s-Third-Sector. pdf

Singer, P. (2007). Economía solidaria: un modo de producción y distribución. Economía social desde la periferia contribuciones latinoamericanas. Editorial Altamira.

UNIRCOOP. (2007). Unircoop: red universitaria de las Américas en estudios cooperativos y asociativos. Université de Sherbrooke. 20007-5(1). 